\title{
A EXTENSÃO UNIVERSITÁRIA NA AMÉRICA LATINA: PERCURSOS ACADÊMICOS E SOCIAIS ${ }^{1}$
}

\author{
UNIVERSITY EXTENSION IN LATIN AMERICA: ACADEMIC AND SOCIAL PATHS
}

\author{
Ail Conceição Meireles Ortiz ${ }^{2}$, Erick Kader Callegaro Correa ${ }^{3}$, \\ Juliane Marschall Morgenstern ${ }^{4}$, Liane Batistela Kist ${ }^{5}$ e Marcio Tascheto da Silva ${ }^{6}$
}

\section{RESUMO}

Este artigo apresenta uma discussão teórico e prática, em torno de elementos, que perpassam os percursos acadêmicos e sociais da extensão universitária na América Latina. A extensão compreende importante função universitária, juntamente à pesquisa e ao ensino, diante do contexto da educação superior. A extensão Latino Americana, que se distancia da mera transferência de tecnologia e do assistencialismo social, tem em Paulo Freire um dos seus grandes formuladores. As ações extensionistas, nos Cursos de Licenciaturas, integram o Programa Educação, Cultura e Comunicação. O Projeto de Extensão Integrador das Licenciaturas, abrange o tema Integração Universidade/Escola/ Comunidade, sendo desenvolvido por subprojetos, a cada semestre dos Cursos, por meio de disciplinas extensionistas. As ações projetadas e realizadas à promoção da curricularização da extensão foram examinadas sobre os indicadores, revelando evidências importantes, como a aderência aos Programas de Extensão Institucionais, o alinhamento às concepções de extensão universitária, baseada no efetivo compromisso social, a incorporação de canais comunicativos de escuta aos territórios de ação extensionista, a promoção de ações, que garantam o protagonismo estudantil, a promoção de análise teórico-prática das ações desenvolvidas, por meio da produção de conhecimentos, o fortalecimento da formação acadêmica e contribuições sócio educacionais efetivas aos territórios educativos (espaços formais e/ou não formais locais). As ações extensionistas em desenvolvimento da Universidade Franciscana, um recorte da educação superior no Brasil, e assim, compondo a realidade latino-americana, se manifestam fortalecidas sobre indicadores que sinalizam já, uma caminhada de significados socioeducacionais significativos, tanto à comunidade universitária, como aos integrantes dos territórios. As ações empreendidas, neste movimento de curricularização da extensão, em cursos de Licenciatura, têm revelado contribuições efetivas sobre o processo de formação acadêmica e profissional, pelo desenvolvimento de habilidades e competências docentes fundamentais ao futuro educador, que projeta construir sua profissão, sobre bases socioeducacionais identificadas ao contexto social local e nacional, portanto, atrelado ao desenho do contexto latino-americano.

Palavras-chave: Contexto Latino-americano; Territórios; Educação Superior; Curricularização da Extensão.

\section{ABSTRACT}

This article presents a discussion from theoretical and practical elements surrounding the academic and social paths of university extension in Latin America. In Latin America, extension has a broad scope of historical

1 Estudo teórico-prático acerca da Extensão na Educação Superior da América Latina e a Curricularização da Extensão nas Licenciaturas UFN, Santa Maria, RS, Brasil.

2 Professora Coordenadora da Curricularização da Extensão nas Licenciaturas/UFN, Santa Maria, RS, Brasil. E-mail: ail@ufn.edu.br 3 Professor Coordenador do Curso de Letras/UFN, Santa Maria, RS, Brasil. E-mail: erick@ufn.edu.br 4 Docente do Curso de Pedagogia/UFN, Santa Maria, RS, Brasil. E-mail: liane@ufn.edu.br 5 Docente do Curso de Letras/UFN, Santa Maria, RS, Brasil. E-mail: julianemorgenstern@ufn.edu.br 6 Docente do Curso de História/UFN, Santa Maria, RS, Brasil. E-mail: marciotascheto@ufn.edu.br 
constructions that conducted a genuine thought, marked by the historicity of this subcontinent. Latin American extension, which distances itself from a mere transference of technology and social assistencialism, has Paulo Freire as one of its most important founders. Extension practices are, then, within the scope of the Education, Culture and Communication of the Franciscan University. The Integrating Extension Project of the licentiate courses approaches the theme of Integration Among University/School/Community, and is being developed by subprojects in each semester, by extension disciplines. The projection and realization towards the promotion of the curricularization of extension were examined upon indicators, revealing important evidences, such as adherence to Institutional Extension Programs, alignment to university extension conceptions, based upon the effective social commitment, incorporation of communicative channels of listening of territories of extension action, action promotion that guarantee protagonist students, promotion of theoretical and methodological actions of actions by means of knowledge productions, the strengthening of academic formation and effective social and educational contributions to educational territories (formal and informal spaces). Extension action in development at the Franciscan University, a part of Brazil's higher learning system, constitutes itself as a LatinAmerican reality and manifests itself strengthened upon indicators that already signal a trajectory of social and educational meaning as to the university community as agents of territories. Such actions, in this movement from the extension curricularization, in licentiate courses, have been revealing effective contributions towards the academic and professional formation by the development of abilities and competences that are fundamental for the teaching practice as a future educator that projects the construction of their own profession upon social and educational bases identified in local and national contexts, hence attached to the Latin-American picture.

Keywords: Latin American Context; Territories; Higher Learning; Extension Curricularization.

\section{INTRODUÇÃO}

A extensão compreende importante função universitária, juntamente à pesquisa e ao ensino, diante do contexto da educação superior. O processo de constituição da educação superior na América Latina, se dá, de forma paralela, a um movimento de reconfiguração e realinhamento das políticas educacionais como um todo, em razão das implicações e resquícios do colonialismo histórico, que firmou as raízes da estrutura sociopolítica, econômica e cultural em décadas pretéritas, deste recorte continental latino-americano.

Este artigo apresenta uma discussão teórico e prática, de elementos interferentes nos percursos acadêmicos e sociais da extensão universitária na América Latina, tendo como eixos pontuais para este exame, uma breve contextualização do panorama educacional latino-americano, focalizando a educação superior e a extensão universitária.

O trajeto desta análise atinge, em momento final, aspectos caracterizadores do processo de curricularização da extensão universitária, em uma Instituição de Ensino Superior brasileira, A Universidade Franciscana, situada na cidade de Santa Maria, RS, Brasil.

\section{Focalizando a educação superior no contexto educacional da América Latina}

O espaço mundial presentifica o acirramento dos efeitos da expansão do sistema capitalista. Este processo histórico multidimensional constitui a globalização, compreendendo, portanto, a ocorrência 
de manifestações políticas, socioeconômicas, culturais e ambientais, de forma interligada sobre o espaço mundial. Bem como fala Sene $(2003,18)$, a dimensão espacial atravessa todas as outras e é atravessada por elas, porque as manifestações socioeconômicas, culturais e políticas da globalização materializam-se no espaço geográfico e moldam-no, assim como são moldadas por ele. As repercussões da globalização abrangem a intensificação de políticas econômicas, que atuam com unicidade sobre o planeta. O termo globalização se propagou diante de universidades norte-americanas, em meio a grupos de administradores e empresários, que buscavam aprofundar estratégias para a expansão do mercado financeiro. Esta nova roupagem denominada "globalização" representa, de forma real, um neoimperialismo ou imperialismo contemporâneo. O sistema capitalista se configura, a partir de diferentes formas de produção e acumulação, desenhando uma estrutura social e espacial hierarquizada e estratificada. Sobre este espaço em construção, elementos sociais e naturais sofrem efeitos de práticas econômicas hegemônicas sobre feições competitivas e de valor capital. As feições expansionistas, de caráter eminentemente economicista, são as mesmas evidenciadas sobre tempos históricos marcados pela corrida colonial. Assim afirma, de forma clara, Sene (2003 p. 37),

As origens mais remotas da globalização podem ser recuperadas na virada do século XV para o XVI, quando se iniciou a mundialização do capitalismo no contexto das Grandes Navegações, quando se iniciou a constituição da economia-mundo capitalista...

Este fenômeno denominado globalização é caracterizado por novos mecanismos, ou melhor, por estratégias bem-sucedidas de regulação da vida das nações em todo o mundo. O avanço técnico-científico-informacional garantiu, de forma eficiente, a aceleração da competitividade e da produção entre os países do sistema-mundo. Percebe-se a crescente aproximação espacial, em tempo reduzido. Em momentos iniciais da expansão capitalista a noção de espaço era relativa. A limitação de técnicas de deslocamento e comunicação impunha a ideia do desconhecimento do planeta. O mapa do mundo era restrito. O mundo constituía o lugar; e não, a ideia de outros lugares. Os lugares constituíam-se parte do mapa-múndi em tempos distintos. Hoje, os discursos ideológicos atingem a todos (as), por uma mídia tendenciosa, carregada de simbologismos inquestionáveis. As identidades espaciais locais perdem força para a massificação de uma cultura e uma economia voltada à produção. Este processo de internacionalização do capital se expande mundialmente, emergindo diferenças-desigualdades, como efeitos, sobre a diversidade espacial. Nesta ideia reforça Hardt; Negri, (2006, p.138),

\footnotetext{
A expansão global do capitalismo, entretanto, não constituiu um processo uniforme nem unívoco. Em várias regiões e entre diferentes populações o capitalismo desenvolveu-se de modo desigual: deu guinadas para frente, hesitou e se retirou segundo uma variedade de caminhos diversos.
}

Este cenário espacial multidimensional sucumbiu ao espaço latino-americano, passando a direcionar a vida política, socioeconômica, cultural e ambiental sobre esta lógica padrão. Caminhamos 
sobre regras do poder econômico. Como ressalta Santos (2000, p. 11), a atual globalização exclui a democracia. A globalização é, ela própria, um sistema totalitário. Estamos em um mundo que nos reclama obediência. A historicidade latino-americana exige reconstruir respostas qualificadas, autênticas aos pelos territórios. As nações da América Latina buscam práticas de significação em seus próprios sujeitos históricos. Não caminhamos, historicamente, de forma igual às nações direcionadoras da globalização. A identidade deve determinar e não subjugar. O nosso singular processo de construção histórica justifica nosso projeto social identitário. Nesta ideia, chamamos Touraine (1994, p. 70),

\footnotetext{
Para alguns a correspondência da atividade econômica e da organização social forma a infraestrutura que determina todas as formas de vida política e cultural, ideia que introduz o determinismo econômico, porém mais importante é a afirmação da unidade de todas as formas da vida coletiva como manifestações de uma capacidade e de uma vontade de autoprodução e de autotransformação da sociedade.
}

As práticas econômicas caracterizadoras da globalização associam-se a argumentos neoliberais, baseados no modelo político-econômico Keynesiano. Bem destacado nas palavras de Bianchetti (1999, p. 88), a característica mais importante do neoliberalismo em relação a outras propostas neoliberais é a ampliação do raio de ação da lógica de mercado. Neste caminho seguem reformas educativas em várias nações da América Latina. A implantação dessas reformas atende aos objetivos e metas de acordos para financiamentos de recursos provenientes do Banco Mundial e do Banco Interamericano de Desenvolvimento. Como fala ainda Bianchetti (1999, p. 93), quando se refere às políticas educacionais, elas dependem das condições políticas de uma conjuntura histórica, mas também das características e do poder dos grupos hegemônicos. Os indicadores conceituais destas reformas educativas: eficiência, equidade, qualidade, conciliação e capacitação de recursos humanos podem ser examinados sobre a dimensão de uma qualidade sócio-histórica, em que se associe a esta análise, verdadeiro significado de excelência educativa. Eficiência, diante de avaliações do processo educativo, deve ser compreendida como a emergência de resultados produtivos em consequência da incorporação de propostas pedagógicas voltadas à formação humana em suas dimensões ética, humanista, interventora e ativa. Sem deixar de atender aos valores e competências à inserção sobre o mundo do trabalho. A equidade, entendida como a promoção de acesso igual, por merecimento e condições cognitivas satisfatórias; e não, pela promoção de mecanismos de acesso facilitadores e assistencialistas, e que exijam padrões mínimos. Qualidade, indicador educacional pretendido em efeito consequente ao incremento de infraestrutura básica aos espaços escolares. Infraestrutura posta em movimento pela atenção a aspectos possibilitadores a uma atividade pedagógica, que abranja equipamentos em quantidade e em funcionamento, recursos humanos capacitados e valorizados, espaço físico adequado e em condições satisfatórias de acesso igual a todos. Recursos humanos com oportunidade de acesso à formação inicial e continuada, em espaços acadêmicos, suscetíveis à produção intelectual e promoção do autodesenvolvimento profissional; e não, mero instrucionismo tecnificado. 
As postulações destes acordos não são publicizadas, de forma evidente, mas o cotidiano da vida nacional manifesta um vocabulário coerente aos planos destes financiadores de verbas públicas. A realidade educacional latino-americana aponta para sistemas de ensino em funcionamento sob condições precárias. Estes conceitos já haviam incorporado políticas neoliberais, como fala Rodriguez (2004, p. 18), estes conceitos já haviam sido levantados como lemas do desenvolvimento econômico durante os anos de 1950, quando se instalou nesses países a teoria do capital humano. Esta estrutura basilar de políticas educacionais busca responder a demandas de setores produtivos, desconsiderando a possibilidade de formação humana em seus aspectos éticos, estéticos, sociopolíticos e cívico. Pressupõe-se a formação para um mundo do trabalho emergente.

É notória a relevância decisiva da retórica política, que se atribui à educação na consolidação de processos de desenvolvimento ao longo da história das nações, tanto desenvolvidas quanto subdesenvolvidas. As nações latino-americanas vem sendo palco de políticas de desobrigações governamentais com uma educação de qualidade e que atinge grande parcela popular, afirmando claramente, um quadro de negação a concepções de democracia, igualdade e justiça social, educação, escola, participação, autonomia e cidadania. Confirmando, que no bojo do atual projeto de desenvolvimento está o mercado como cerne do neoliberalismo7. E não, o aperfeiçoamento e respeitabilidade ao ser humano. É clara a contradição, historicamente observada, entre o discurso e a ação governamental brasileira frente às políticas públicas, especialmente àquelas das áreas sociais. O acirramento da crise educacional, vivida nestes países tem vindo a reforçar o conjunto de políticas públicas adotadas por seus governos, em que obedecem à matriz definida pelo Banco Mundial, Banco Interamericano de Desenvolvimento e pela CEPAL (Comissão Econômica para a América Latina). Os países alinhados a essa política neoliberal vêm controlando as verbas destinadas à educação. Os encontros reunindo expressivos Organismos Internacionais de Financiamento (BIRD, BID, USAID) passam a incluir em seus programas de investimentos, também, projetos educacionais para a América Latina e América Central. Este novo enfoque - implementado pelos grandes Organismos Internacionais de Financiamento - destinado ao rumo desenvolvimentista dos países pobres, segundo tal filosofia, "visa incentivar uma maior equidade na distribuição do conhecimento, de forma que a educação representa de fato, uma ferramenta eficaz na qualificação da mão-de-obra necessária ao desenvolvimento econômico e contra a reprodução da miséria, da violência e da instabilidade sociopolítica na região". Assim, esses preceitos, que permeiam os planos financeiros desses Organismos Internacionais com vista à educação latino-americana, estão atrelados a uma concepção economicista da educação e não humanística. Entendendo a educação de qualidade como algo mensurável, onde o educando deve apenas acumular

7 Neoliberalismo, segundo Bianchetti (1997, p. 50), é o movimento político-econômico heterogêneo, consolidado nos países capitalistas desenvolvidos, em meados da década de 70, cuja proposta econômica significa o retorno aos princípios ortodoxos do liberalismo, ou seja, às propostas da economia clássica como única alternativa de superação da crise pela qual passam as sociedades. Na educação surge a Teoria do Capital Humano, em que a educação é o principal capital humano enquanto produtora de capacidade de trabalho, potenciadora do fator trabalho. Neste sentido é um investimento como qualquer outro. 
conhecimentos. Isolando-o de um processo de formação como sujeito social. Esta realidade sociopolítico-educacional vem ditar, de forma autoritária, as concepções educacionais que direcionam os sistemas de ensino nos países integrantes da América Latina. As concepções educacionais de setores hegemônicos, utilizadas para manutenção da situação generalizada de exclusão social a que se submete a sociedade latino-americana, diferem de concepções educacionais reivindicadas hoje por muitos segmentos populares organizados. Portanto, fortalecer a luta pela qualidade social, em meio ao curso acelerado de globalização econômica e cultural, implica providenciar uma educação, tanto para o desenvolvimento econômico, social, cultural e político, como para assegurar direitos básicos de cidadania e liberdade. Em Fiori (1991, p.83) podemos perceber a educação como legítimo processo de condução à construção de uma consciência histórica.

A educação é esforço permanente por constituir-se, buscando a forma histórica na qual possa reencontrar-se consigo mesmo, em plenitude de vida humana, que é, substancialmente, comunhão social. Esse reencontro que, no horizonte do respectivo momento histórico, coloca o homem em seu lugar próprio, tem um nome adequado: autonomia e liberdade.

Reafirmando a importância em educar na perspectiva de preparar para uma produção social pela participação, como prática democrática, a que se atinja uma sociedade diferente, que venha assegurar qualidade social, destaco a citação de Gandin apud Kowarzik (1988, p. 18): "Educar é dotar a população de instrumentos básicos para a participação na sociedade". O momento histórico, que presenciamos é de extrema fragilidade nos procedimentos humanos que dão significado à instauração de um estado de, no mínimo, aproximação à emancipação. O Estado, como instituição mediadora de procedimentos que garantam condições iguais de vida digna à sociedade, passa a estabelecer práticas governamentais inculcadas por uma ideologia estranha aos interesses populares; e muito familiar aos interesses de países desenvolvidos, alijando de forma dilacerante o verdadeiro processo de desenvolvimento nacional. A educação se dá sobre este contexto político, econômico, social, espaço-temporal. O maior desafio da educação atual é formar um homem/mulher, que atinja a consciência de que o "seu bem-estar" é também o "bem estar" do outro, numa íntima relação de consciência de si e consciência de mundo. E, a partir desta revelação consciente, o sujeito histórico passará a promover a vida humana, num trato equânime a todas as entidades humanas e não humanas. A fronteira entre um comportamento humano interventor, que garanta a concretização histórica, e um comportamento alienado, alheio à intencionalidade transformadora, está no momento da sensibilização das questões mais urgentes do seu tempo. Quando consideramos decididamente uma atitude consciente na ação histórica, lembramos Damke (1995, p. 97): "Se a conscientização indica o processo de inserção crítica dos seres humanos na ação transformadora da realidade, ligam-se a ela duas tarefas fundamentais: desmistificar a realidade e agir sobre ela para modificá-la."

Esta conjuntura sociopolítica educacional latino-americano perfila, de forma natural, também, os espaços universitários. O movimento globalizatório vem acirrar demandas urgentes da educação 
superior na América Latina, que não respondem, de forma rápida e positiva, pois, os processos de constituição desta modalidade de ensino, se deu pela instauração de modelos europeus, em meio aos cenários coloniais, bem como toda a configuração social, política, econômica deste continente em evidência. As primeiras unidades universitárias latino-americanas seguiam padrões franceses, alemães e espanhóis, reafirmando, portanto, a herança de um centro mundial europeu, sobre uma realidade periférica com uma identidade sócio-histórica e cultural, distintamente oposta à hegemonia ocidental. Muitas marcas coloniais se enraizaram sobre a estrutura universitária destas nações, por muitas décadas, como a elitização ao acesso, priorização para uma formação religiosa, filosófica e jurídica. A partir, então, da Reforma de Córdoba, no início do século XX, passa-se a instauração da autonomia universitária, da mudança no processo de ensino e de docência, a democratização da universidade, tanto em sua gestão, como na garantia da permanência de estudantes de todos os grupos sociais. O marco “Documento da Reforma Universitária”, reafirmado em 1918, na Argentina, dá novos rumos à busca por uma identidade própria às universidades latino-americanas.

O ensino, a pesquisa e a extensão universitária passam a desvendar e alinhar sua funcionalidade em consonância à realidade latino-americana. O cenário da educação superior em nações latino-americanas tem sofrido muitas e importantes alterações ao longo das últimas três décadas: observa-se uma significativa ampliação da taxa de matrícula, nestes países; maior diversificação institucional; incremento da participação do setor privado na prestação dos serviços educacionais, incluindo a oferta transnacional; a redução progressiva do investimento público no setor, sendo as universidades públicas cada vez mais sugestionadas a buscarem novas fontes de financiamento (SOUZA, 2018).

Sendo assim, verificou-se um forte processo de privatização, com a entrada de novos atores no campo acadêmico, que se diferenciavam não somente pelo seu caráter administrativo mercantil, mas também pela sua heterogeneidade institucional, com a ascensão de organizações não universitárias que se dispuseram a atender à crescente demanda por formação de nível terciário (BIANCHETTI; SGUISSARDI, 2017).

As transformações que marcam este período, contudo, fazem parte de um processo mais amplo e complexo de dinâmicas globais, que envolvem a centralidade assumida pelos OIs e outros atores na proposição/indução de políticas e a reconfiguração do papel do Estado (LIMA, 2005), fundamentadas pelas ideologias da "sociedade do conhecimento" (BINDÉ, 2007) e da "globalização" e as aceleradas transformações decorrentes do processo de mundialização do capital (CHESNAIS, 1996).

Na contemporaneidade as Instituições de Ensino Superior Latino-americanas têm observado importantes urgências, como a emergência de financiamentos privados com objetivos de mercado e não, a consolidação da função universitária, o surgimento de novas áreas profissionais, pressões de Organismos Financeiros e Econômicos Mundiais para direcionamento da pesquisa à determinadas áreas da ciência e tecnologia, ampliação de programas de Educação a Distância, o acelerado curso da privatização da educação superior, a necessidade de inclusão de segmentos sociais historicamente 
marginais aos bancos universitários e a busca por formas alternativas à incursão das novas tecnologias diante do currículo do ensino superior.

A educação superior na América Latina, seja ela sobre espaços públicos e/ou privados se manifesta em construção, impondo passos céleres, que atinjam, não apenas, qualidade na oferta de inovação científica e tecnológica, mas também, equidade de acesso, constituição de um saber para fim social e, acima de tudo, promoção de oportunidade à geração de produtos inovadores, que contribuam ao desenvolvimento social.

\section{Aproximando a extensão universitária na América Latina e o pensamento pedagógico freiriano}

A extensão universitária na América Latina possui um amplo escopo de construções históricas que a conduziram a um pensamento genuíno, marcado pela historicidade desse subcontinente. Do manifesto centenário de Córdoba ${ }^{8}$ aos debates atuais sobre extensão universitária no âmbito da ULEU $^{9}$, passando pelos importantes aportes e experiências da educação popular no Brasil dos anos 1960 e 1980, temos um acúmulo de balizadores históricos que marcam a compreensão singular da América Latina no que tange a relação do Ensino Superior com a sociedade e a sua real implicação em sociedades tão marcadamente desiguais.

A crítica a extensão universitária difusionista (TOMASINO, 2016), ao entendimento mecanicista da educação (FREIRE, 1992), ao assistencialismo social e pedagógico (Resolução CNE/CES, $N^{\circ}$ 7, de 18 de dezembro de 2018/ MEC), demonstra a busca por compreensão e prática das ações extensionista em diálogo com essa rica contribuição do pensamento pedagógico latino-americano. Contribuição amparada no contexto histórico das diversas lutas sociais que marcam a realidade dos diferentes países que, quando interseccionadas, apontam para o diálogo necessário das diversas experiências de extensão universitária vicárias a esse processo.

A extensão Latino Americana, que se distancia da mera transferência de tecnologia e do assistencialismo social, tem em Paulo Freire um dos seus grandes formuladores. Sem cairmos na armadilha da personalização de um processo histórico-pedagógico feito de muitos coletivos, movimentos e lutas diferentes, ressaltamos o papel sistematizador dessas aprendizagens dos oprimidos promovida pelos escritos-experiências de Freire. Da alfabetização de adultos em Angicos aos Círculos de Cultura espalhados (e interrompidos) pelo Brasil dos anos 1960, Freire "traduziu” uma forma de fazer

\footnotetext{
8 Manifesto redigido pelos estudantes da Universidad de Córdoba, Argentina. Tinha como principal aspecto a reivindicação de reformas universitárias que atendessem a realidade dos países da América Latina e o protagonismo dos estudantes no processo de aprendizagem.

9 União Latino-Americana de Extensão Universitária é uma instituição não governamental sem fins lucrativos, que reúne organizações universitárias, universidades e instituições de Ensino Superior, com a finalidade de fortalecer a extensão universitária na perspectiva dialógico-crítica.
} 
educação em que o "currículo" nascia das experiências concretas das vidas dos camponeses e operários. Mais do que "Ivo ver a uva" como ensinavam as cartilhas de alfabetização da época, Freire deu visibilidade a importância dos contextos semânticos do universo do trabalho e dos trabalhadores. Dito de outra maneira, Freire compreendeu que a leitura do mundo, do mundo do trabalho e suas contradições, deveria ser primordial para a aprendizagem dos educandos.

A partir da abordagem freireana nascia, não só uma educação mais eficaz para o enfrentamento do analfabetismo, como também uma perspectiva emancipatória da educação como ato de liberdade. São as existências concretas vividas pelos educandos que deveriam ser mobilizadas para o ensino aprendizagem, situando a palavra e o mundo em um processo histórico de possível mudança. Aprender a ler significava não só a decodificação dos mistérios da linguagem escrita, mas o próprio desvelamento do mundo.

Mas o que dá experiência histórica do "Método Paulo Freire" podemos correlacionar com a história imediata da extensão universitária na América Latina e no Brasil?

Três aspectos podem ser destacados e relacionados aos desafios atuais da extensão universitária e o pensamento freireano na América Latina e no Brasil: 1. Protagonismo dos estudantes; 2. a Curricularização da extensão; 3. a Territorialização da Universidade.

De forma articulada, esse conjunto de desafios apontam para interfaces importantes na concepção freireana de educação. Em primeiro lugar, partir da realidade dos educandos como sinalizava Freire, implica no reconhecimento dos estudantes como sujeitos dos processos de aprendizagens. No entanto, não diz respeito somente a pensar em técnicas, métodos, estratégias e metodologias, mas também no alargamento das fronteiras da educação universitária, a forma com que, a partir da realidade dos educandos, ela própria, universidade, "vai à realidade". Criar outros itinerários educativos que dialoguem com os conteúdos, que "surgem" não de forma espontânea, mas do encontro intencional das pedagogias universitárias com os territórios, pode significar percursos formativos mais autônomos e recheados de sentido. Sobretudo, no âmbito de cursos de formação de professores, ao mobilizar interações sociais e de escuta sensível dos diferentes sujeitos, algo que a extensão universitária quando pensada como um espaço formativo, constitui-se como vetor para inovações pedagógicas baseadas no protagonismo dos estudantes.

Em segundo lugar, a curricularização da extensão universitária, processo em curso nas instituições de ensino superior que visa a materialização da meta 12.7 do PNE, pode configurar-se como uma excelente oportunidade de ressignificação curricular. Uma vez entendida como bem mais do que uma interface da extensão nos currículos, compreendendo sua potência plena de ampliação do espaço formativo, a curricularização da extensão configura-se como um modo de aprendizagem que pode proporcionar uma inovadora pedagogia universitária. Educar a partir dos territórios e pela experiência de situações reais, colocando o educando em contato com inúmeras vivências, instiga os currículos acadêmicos a repensarem suas estratégias, saberes e práticas de ensino. 
Desta forma, o protagonismo estudantil e o diálogo entre currículo e a experiência social, nos leva a mais desafiadora proposição que as instituições de ensino superior vem enfrentando: romper com a histórica desterritorialização das nossas práxis pedagógicas. A territorialização da universidade passa pela dialética espaço-tempo das relações educativas. A acepção do território como um espaço de aprendizagem nos conduz para a compreensão da ativação pedagógica dos espaços sociais como oportunidades formativas no âmbito da relação entre universidade e sociedade. O que implica pensar os desdobramentos do território como lugar onde não só a aprendizagem acontece, mas também emite outros conteúdos e torna-se um espaço ético-político de mudança. Tempos, espaços e a produção do conhecimento são desafiados a ressignificarem suas lógicas, dado que os territórios produzem outras narrativas, tensionando a educação formal ao encontro com outros sujeitos e pedagogias (ARROYO, 2012).

Inúmeras experiências institucionais vêm demonstrando que o estudante que perfaz outros itinerários formativos em contato com vivências comunitárias, em contextos sociais mais diversificados, por meio de programas e projetos de extensão, possui oportunidades mais sofisticadas e consistente de articular suas formações técnicas e cidadãs durante a graduação. Compreendemos que essa aproximação entre o pensamento pedagógico freireano em seus postulados humanizadores da educação como prática da liberdade, com os desafios da extensão universitária contemporânea, pode gerar uma identidade mais consistente do que queremos construir com as nossas práxis pedagógicas no Ensino Superior em uma instituição comunitária, como tentaremos demonstrar na experiência a seguir.

\section{Conhecendo o processo de curricularização da extensão nas Licenciaturas da Universidade Franciscana, Santa Maria, RS, Brasil: produções e significações}

A curricularização da extensão representa a inserção teórico-prática, sobre os currículos acadêmicos, de uma concepção curricular ampla, em indissociabilidade às demandas sociais, às identidades de cada curso, e aos contextos histórico-sociais e culturais. Estas práticas curriculares devem constituir-se em ações efetivamente promotoras de momentos formativos significados por inserção com e nos contextos socioespaciais, em movimento de interatividade horizontal. As ações de caráter extensionista, sobre nos Cursos de Licenciatura da UFN, vêm sendo executadas sob a forma de subprojetos, alinhados a um ou mais Programas de Extensão Institucional e ao Projeto de Extensão Integrador. As ações extensionistas, nos Cursos de Licenciaturas, integram o Programa Educação, Cultura e Comunicação. O Projeto de Extensão Integrador das Licenciaturas, abrange o tema Integração Universidade/Escola/ Comunidade, sendo desenvolvido por subprojetos, a cada semestre dos Cursos, por meio de disciplinas extensionistas. Em especial, mobilizados pelas disciplinas de Seminários Integradores. Esta disciplina integra o currículo das Licenciaturas, focando em temáticas pontuais. O Seminário Integrador I destaca o tema investigação e contextualização da realidade social; 
o Seminário Integrador II, relações interpessoais na comunidade escola; o Seminário Integrador III, sistemas de ensino e mecanismos de gestão; o Seminário Integrador IV, atuação em ambientes não formais; o Seminário Integrador V, modalidades de ensino e diversidades; o Seminário Integrador VI, pesquisa em cenários diversos e o Seminário Integrador VII, focaliza atividades integradoras com a comunidade escolar. A operacionalização desta estrutura curricular se dá pela definição de sujeitos e respectivas atribuições a serem desenvolvidas.

Há a firme percepção, de amplos e eficientes benefícios acadêmico-sociais, diante da inserção sobre a extensão universitária, emergindo contribuições à toda a comunidade acadêmica e sociedade em geral. A gestão institucional, se manifesta fortalecida pela proatividade e visibilidade positiva do desempenho funcional universitário; às comunidades, territórios-objetos da ação extensionista, tem na promoção da escuta e compartilhamento de saberes, rumos viáveis, em busca de estratégias inovadoras e concretas às demandas sociais; a qualidade da formação profissional dos estudantes universitários, se revela corporificada de conhecimento e subsídios contribuintes, pela inserção na realidade, foco de futura atuação profissional. As ações projetadas e realizadas à promoção da curricularização da extensão foram examinadas sobre os indicadores, revelando evidências importantes, ao seguimento das atividades desenvolvidas:

a) Aderência aos Programas de Extensão Institucionais: As ações empreendidas ocorrem, em consonância aos Programas de Extensão definidos sobre as grandes políticas institucionais, desde o momento da construção do Projeto Integrador de Extensão, bem como da elaboração dos Subprojetos de Extensão, que direcionam os denominados Seminários Integradores.

b) Alinhamento às concepções de extensão universitária, baseada no efetivo compromisso social: O planejamento e desenvolvimento das ações extensionistas seguem o rigor conceitual, sobre a dimensão de horizontalidade na construção compartilhada de saberes, por exercício de superação da dimensão assistencialista. Reafirmando o compromisso social das Universidades, evidenciando, de forma efetiva a corresponsabilização na busca à análise coletiva de questões e demandas da sociedade, como pressuposto à aproximação de soluções originais, atentando às identidades culturais locais.

c) Investimento em práticas universitárias disruptivas: As ações extensionistas, implementadas sobre um ideário teórico, calcado em concepções dialógicas e colaborativas, têm revelado passos bem fortes e seguros na direção do rompimento a uma ordem usual, de caráter assistencialista, muito marcada sobre as Universidades brasileiras.

d) Incorporação de canais comunicativos de escuta aos territórios de ação extensionista: O princípio de dialogicidade e dialeticidade imbricado sobre dimensões extensionistas, embasam as ações institucionais, e seguem a postura de escuta aos territórios, recortes espaciais em foco, na forma de produção de diagnósticos técnico-científicos, que passam a expressar os perfis, demandas, identidades dos locais, lugares de intervenção acadêmica. Este território, objeto de ingerência extensionista, dos cursos de licenciatura, compreende espaços sociais, sobre contextos públicos e/ou 
privados, formados por complexas relações de poder, sejam elas em âmbito restrito, quanto em maior amplitude. Nos anos de 2020/2021 passou-se a utilizar o vasto potencial de plasticidade do meio digital e possibilitou, portanto, a criação de um espaço virtual para conectividade. O planejamento das ações extensionistas nas escolas estava previsto para ocorrer, a partir da metodologia de projetos, construídos pelas demandas apresentadas por elas. Entretanto, instaurada a situação de pandemia em razão do Covid-19, foi preciso replanejar as estratégias para a extensão a serem desenvolvidas por meios digitais. Para tanto, os professores responsáveis pelos Seminários Integradores criaram um espaço virtual compartilhado, chamado de Universidade \& Territórios. O espaço virtual "Universidade \& Territórios" teve como objetivo promover um ambiente online de interação e aprendizagem, envolvendo os acadêmicos das licenciaturas, docentes de Cursos de Licenciatura da UFN e integrantes da comunidade escolar. Segundo Saraiva (2007), a extensão possibilita ao acadêmico a experiência de vivências significativas que lhe proporciona reflexões acerca das grandes questões da atualidade e, com base na experiência e nos conhecimentos produzidos e acumulados, o desenvolvimento de uma formação compromissada com as necessidades nacionais, regionais e locais, considerando-se a realidade brasileira.

O espaço virtual de compartilhamento de saberes foi organizado com a intenção de operacionalizar um ambiente para a escuta e diálogo com os integrantes dos territórios, nos quais as práticas extensionistas aconteceram. A culminância de ações, com vista à efetivação do processo de curricularização da extensão, desenvolvido nos Cursos de Licenciatura da UFN, ao longo do ano de 2020 promoveu a organização de um canal no youtube (https://www.youtube.com/channel/UCrVyuJG-czLR_LGVnSbDYEA), organizado para compartilhamento das práticas educacionais digitais aos integrantes dos sistemas de ensino municipal e estadual. Este repositório de práticas educacionais digitais constitui uma produção dos Cursos de Licenciatura da UFN e do Mestrado em Ensino de Humanidades e Linguagens/UFN.

e) Promoção de ações, que garantam o protagonismo estudantil: Os acadêmicos, estudantes universitários, em especial, de cursos de licenciatura, passam a ouvir os sujeitos ativos da realidade escolar, conhecendo-os, interagindo e percebendo, já em momento de formação, o contexto educacional, e, a partir deste conhecimento, serão conduzidos ao estabelecimento de aproximações entre fundamentos teóricos-metodológicos e a prática pedagógica em seu movimento real.

f) Promoção de análise teórico-prática das ações desenvolvidas, por meio da produção de conhecimentos: A inserção sobre o mundo da escola, representa exercício formativo potencial, aos alunos em formação docente, porém, sobre firme exame crítico-reflexivo, que conduza à emergência de variáveis implicadas sobre êxito e fragilidades da atividade educativa escolar na contemporaneidade. A discussão em espaço acadêmico, de elementos resgatados, por diagnósticos técnico-científicos, está sendo norteada por referenciais teóricos, que atendem a novas condutas pedagógicas, como possibilidades à superação do distanciamento entre escola e vida. 
g) Promoção de avaliação e autoavaliação da gestão institucional: O processo de incorporação da curricularização da extensão tem conduzido à atitudes diagnósticas, racionais e prospectivas da equipe gestora, como importante postura empreendedora ao atendimento às metas institucionais.

h) Fortalecimento da formação acadêmica: As ações de caráter extensionista são planejadas, pelos docentes responsáveis pelas disciplinas afins, portanto, prevendo atividades mobilizadoras do protagonismo estudantil. Segundo Tommasino (2016) a extensão crítica tem objetivos centrais: um vínculo com a formação dos universitários e a possibilidade de estabelecer processos integrais, que rompam com a formação profissionalista afastada de um critério de compromisso social dos graduados universitários. Segundo Tascheto (2018), por constituir-se, como presença contextualizada, a extensão possibilita a experiência mobilizadora da aprendizagem de tal forma partícipe e constituidora da subjetividade que decorre dela - aprendizagem - a transformação do meio (mundo). As ações empreendidas têm revelado o fortalecimento da compreensão efetiva do sentido extensionista, como fundamental função universitária, bem como têm evidenciado a produtiva intervenção dos estudantes e a receptividade dos recortes sociais, que estão em interação. Significativos avanços foram percebidos, tanto, em relação ao fortalecimento do processo formativo para a docência, com a ampliação de saberes e a afirmação do compromisso social das universidades, em especial neste momento presente, a emergência do protagonismo estudantil.

i) Contribuições sócio educacionais efetivas aos territórios educativos (espaços formais e/ou não formais locais): Além da disponibilização do Repositório Digital de Práticas Pedagógicas - Universidade \& Territórios, as ações extensionistas nas Licenciaturas tem mobilizado, com amplitude, base teórica e caráter reflexivo, as instâncias acadêmicas e comunitárias, tanto em nível de setores da gestão pública local, como setores da gestão dos sistemas de ensino, concepções, princípios e práticas das Cidades Educadoras. Ao longo do ano de 2020/2021 muitas ações constituíram à geração de conhecimento, no formato de produtos educacionais e/ou objetos de aprendizagem, dentre eles, destacamos: Ação 01: Salas Temáticas Virtuais, onde foram abordados temas comuns, eleitos para o trabalho compartilhado, dentre eles, pandemia - pandemia e impactos no espaço urbano desigual e na educação, veiculados por urbanistas, epidemiologistas, sanitaristas, gestores de sistemas de ensino e de escolas locais - territórios educativos - Objetivos para o Desenvolvimento Sustentável, segundo a Agenda 2030, os ODSs e as modalidades de ensino. Ação 02: Além das salas temáticas virtuais, os professores responsáveis pelos Seminários, junto ao grupo de acadêmicos, organizaram a discussão sobre os Objetivos de Desenvolvimento Sustentável (ODS). A compreensão dos ODS foi importante para a discussão sobre educação no contexto da pandemia. Ação 03: A discussão em torno dos Objetivos para o Desenvolvimento Sustentável impulsionou a programação da XI Jornada Integrada do Meio Ambiente - A JIMA/UFN, cujo tema foi “Agenda 2030 para o Desenvolvimento Sustentável: agravos e perspectivas em cenário pandêmico. Perfilando reflexões em torno da territorialização dos ODSs e das Cidades Educadoras. Fraternidade e vida como proclames sociais!" Os Cursos de 
Licenciatura da UFN, por meio de um espaço virtual compartilhado, denominado Universidade \& Território. A programação envolveu intervenções remotas de docentes e acadêmicos da UFN e pesquisadores de Instituições de Ensino Superior nacional e internacional, ao longo do período de 5 a 12 de junho de 2020. As intervenções ocorreram no site da UFN e redes sociais. Ação 04: Evento Curricularização em pauta: a voz dos territórios, a reflexão universitária e as contribuições compartilhadas. Este momento contou com a interlocução entre representantes dos territórios, acadêmicos e docentes da Universidade. Ação 05: Incursões no território do bairro-centro (em modo remoto). Tratou-se do desenvolvimento de metodologias de investigação do bairro para a construção de processos de aprendizagens que compreendam o centro como um território educativo. Para tanto, serão realizados 4 mapeamentos: (1) Mapa visível; (2) Mapa do Invisível; (3) Mapa das oportunidades Educativas/ espaços de aprendizagens; (4) Mapa dos Parceiros. Ação 06: Produção de mapas, cartografando o território, objeto de ação extensionista. Ação 07: Conversa de Rua (Av. Rio Branco); Biblioteca de Babelga (Vila Belga); Estação da Aprendizagem (Gare da Estação); Diálogos nos territórios delimitados para as ações, visando explorar o currículo do território". Ação 07: Seminário Olhares da Extensão na América Latina I: diálogos inter territoriais. Ação 08: Seminário Olhares da Extensão na América Latina II: intercambiando ações extensionistas exitosas. Ação 09: Podcasts sobre a história local: com integrantes do território. Ação 10: Cenas no Território: a partir da escuta aos integrantes do território, por meio da aplicação de instrumento de pesquisa em formato digital, a sistematização das impressões levantadas acerca dos saberes construídos sobre as relações interpessoais em tempo de pandemia, estão sendo produzidos vídeos. As cenas foram gravadas no espaço interno das Escolas E.E.B. Manoel Ribas e na E. E. E. F. João Belém. Ação 11: Produção de vídeo sobre o tema Códigos da Pandemia. Ação 12: Os acadêmicos (as) dos Cursos de Licenciatura UFN produziram uma Carta poio à Educação Local em tempo de pandemia, em formato de podcast "UNIVERSIDADE \& TERRITÓRIO: carta apoio à educação santa-mariense, em tempo de crise sanitária. Que lugar é este? Que cidade é esta? A cidade educa? Como educar hoje, em contexto pandêmico? Ação 13: Produções de divulgação no Site da UFN; UFN TV; Eventos científicos: Jornadas da Extensão Mercosul - XI Simpósio Nacional de Educação 2020 - Encontro ForExt Câmara Sul 2020 - CIET:EnPED 2020 - Sepe/ UFN 2020. Ação 14: Produção de um podcast: Guia sobre Extensão nas Licenciaturas para a EAD (em formato de objeto de aprendizagem digital): Importantes saberes em torno da extensão universitária: uma construção compartilhada e interativa.

\section{CONCLUSÃo}

As discussões processadas ao longo desta produção textual geraram algumas inferências de relevo, a serem consideradas em atitudes de redimensionamento e alinhamento, diante de uma perspectiva de avanços. As ações extensionistas em desenvolvimento da Universidade Franciscana, um 
recorte da educação superior no Brasil, e assim, compondo a realidade latino-americana, se manifestam fortalecidas sobre indicadores que sinalizam já, uma caminhada de significados socioeducacionais significativos, tanto à comunidade universitária, como aos integrantes dos territórios, porém, ainda se compreendem tímidas, quanto ao atendimento de demandas sociais emergentes. Há necessidade de uma aderência teórica e ideológica às bases de uma pedagogia universitária alinhada aos pressupostos histórico-culturais latino-americanos. O protagonismo estudantil mostra-se em firme trajeto de afirmação, desde uma compreensão das bases teórico-metodológicas da extensão, como da proposição e inserção sobre intervenções sobre o território e produção de conhecimento.

As ações empreendidas, neste movimento de curricularização da extensão, em cursos de licenciatura, têm revelado contribuições efetivas sobre o processo de formação acadêmica e profissional, pelo desenvolvimento de habilidades e competências docentes fundamentais ao futuro educador, que projeta construir sua profissão, sobre bases socioeducacionais identificadas ao contexto social local e nacional, portanto, atrelado ao desenho do contexto latino-americano. Esta aliança de importantes atores institucionais, atrelada às propostas de ações extensionistas, fortaleceu a dimensão da integralização na produção de exercícios interdisciplinares sobre a construção de saberes acadêmicos. A extensão universitária deve promover a consolidação da relevância social e acadêmica, de ações de caráter interativo entre unidades institucionais, que integram a sociedade, para, em dimensão paritária, garantir a promoção de ganhos aos sujeitos envolvidos nestas ações. A formalização dos saberes produzidos por este movimento interativo, se dá, pela sistematização de conhecimentos elaborados, que possam ser registrados em produções científicas, portanto, o tratamento teórico-crítico deve constituir culminância de todo o empenho plural. Por meio das práticas extensionistas das disciplinas supracitadas que discentes são capazes de observar e aplicar conjuntos epistemológicos das diversas áreas do conhecimento, em especial nas disciplinas dos Seminários Integradores. A possibilidade do uso de teorias e abordagens causa, em primeiro lugar, a retenção maior da aprendizagem, porque é possível observar como e por que uma teoria e/ou abordagem foi construída de uma forma específica. Em segundo lugar, ao corpo discente é possibilitado a competência da adaptabilidade e atualização epistêmica, principalmente quando discentes e docente observam fenômenos sociais e suas fragilidades de funcionamento e distribuição de conhecimentos. A teoria, então, é adaptada ao espaço e tempo específicos e, quando necessário, é capaz de sofrer modificações internas e externas, com vistas a sua atualização perante novas práticas discursivas e sociais.

\section{REFERÊNCIAS}

ARROYO, M. Outros sujeitos, outras pedagogias. Petrópolis: Vozes, 2012.

BIANCHETTI, R. G. Modelo neoliberal e políticas educacionais. 2. ed. São Paulo: Cortez, 1999. 
BIANCHETTI, L.; SGUISSARDI, V. Da Universidade à Commoditycidade. Campinas: Mercado de Letras, 2017.

BRASIL, Plano Nacional de Educação (2014-2024_: Lei 13.005, de 25 de junho de 2014.

BRASIL. Plano Nacional de Educação (PNE). Lei no 10.172, de 09 de janeiro de 2001. Aprova o Plano Nacional de Educação e dá outras providências. Legislação Federal, 2001.

CHESNAIS, F. A mundialização do capital. São Paulo: Xamã, 1996.

DAMKE, I. R. O processo do conhecimento na Pedagogia da Libertação: as ideias de Freire, Fiori e Dussel. Rio de Janeiro: Vozes, 1995.

FIORI, E. M. Textos escolhidos: V. II: Educação e política. Porto Alegre: L \& PM, 1980.

FIORI, E. M. Textos escolhidos: V. I: Metafísica e história. Porto Alegre: L \& PM, 1991.

FREIRE, P. Extensão ou comunicação? 10 ed. São Paulo: Paz e Terra, 1992.

MINISTÉRIOS DA EDUCAÇÃO. Da concepção, das diretrizes e dos princípios, 2018. Disponível em: https://bit.ly/3tYO3hK. Acesso em: 30 maio 2021.

SENE, E. de. Globalização e espaço geográfico. São Paulo: Contexto.

SOUZA, J. F. Itinerários Da Internacionalização Da Educação Superior Brasileira No Âmbito Da ALeC. 2018. Tese (Doutorado em Educação, Conhecimento e Inclusão Social) Faculdade de Educação. Universidade Federal de Minas Gerais. Belo Horizonte. 2018.

TOMMAZINO, H. Avances y retrocesos de la extensíon crítica en la Universidad de la República de Uruguay. Revista Másquedós. Tandil: Universidad Nacional del Centro de la Província de Buenos Aires, 2016.

TOURAINE, A. Crítica da modernidade. Rio de Janeiro: Vozes, 1994. 